\title{
RHINOLOGY
}

\section{Endoscopic balloon dilatation of the olfactory cleft - a feasibility study of a novel technique in cadavers}

\section{Dilatazione endoscopica con balloon della fessura olfattoria - studio di fattibilità di una tecnica innovativa su cadavere}

\author{
Osman H. Çam ${ }^{1,2}$, Dafna Gershnabel Milk ${ }^{1,3}$, Fernando Alfaro-Iraheta ${ }^{1,4}$, Grace C. Khong ${ }^{1}$, Claire Tierney ${ }^{5}$, \\ Samuel C. Leong ${ }^{1}$ \\ ${ }^{1}$ The Liverpool Head and Neck Centre, United Kingdom; ${ }^{2}$ Faculty of Medicine, Baskent University, Turkey; ${ }^{3}$ Meir Medical Centers, \\ Department of Otolaryngology-Head and Neck Surgery, Kfar Saba, Israel; ${ }^{4}$ Hospital Central Militar Mexico; ${ }^{5}$ The Human Anatomy \\ Resource Centre, University of Liverpool, United Kingdom
}

\begin{abstract}
SUMMARY
Objective. Smell dysfunctions are common with almost $20 \%$ percent of the population affected. There are no interventional solutions for these patients. The aim of this study is to investigate the feasibility and security of the balloon dilatation technique.

Methods. This paper describes interventional steps and determines the feasibility and safety of endoscopic olfactory cleft dilatation via balloon device. We included 10 nasal cavities in the study and dilated olfactory cleft areas via balloon device.

Results. We could smoothly perform the procedure and did not observe any fractures on the skull base or olfactory cleft of the cadavers after dilatation.

Conclusions. A combination of this intervention with medical treatments can be promising for smell dysfunctions.
\end{abstract}

KEY WORDS: olfactory cleft, balloon dilation, olfactory stenosis, olfactory disorder

\section{RIASSUNTO}

Obiettivo. Le disfunzioni dell'olfatto sono comuni; quasi il 20 per cento della popolazione ne è colpita. Non ci sono soluzioni risolutive per questi pazienti. Lo scopo di questo studio è indagare la fattibilità e la sicurezza della tecnica di dilatazione con palloncino della fessura olfattoria.

Metodi. Questo paper descrive le fasi della procedura chirurgica e valuta la fattibilità e la sicurezza della dilatazione della fessura olfattiva endoscopica tramite dispositivo a palloncino. Abbiamo incluso dieci fosse nasali nello studio e dilatato le fessure olfattorie tramite dispositivo a palloncino.

Risultati. Abbiamo potuto eseguire la procedura senza problemi e non abbiamo osservato alcuna frattura della base del cranio o della fessura olfattiva dei cadaveri dopo la dilatazione. Conclusioni. Una combinazione di questo intervento con trattamenti medici può essere promettente per le disfunzioni dell'olfatto.

PAROLE CHIAVE: fessura olfattoria, dilatazione con balloon, stenosi olfattoria, disordine dell'olfatto

\section{Introduction}

The incidence of olfactory dysfunction is high, affecting approximately $20 \%$ of the adult population ${ }^{1}$. The most common aetiologies are upper respiratory tract viral infection, chronic rhinosinusitis and head trauma ${ }^{2}$. Pre-existing narrowing or stenosis of the olfactory cleft can also result in hyposmia ${ }^{3}$. The management of olfactory dysfunction is focused on treating any reversible aetiology. Topical intranasal steroids remain the primary treatment modality ${ }^{4}$. Olfactory training, first described by Hummel et al. in 2009, is a crucial adjunct, especially in patients with post-viral olfactory dysfunction ${ }^{5}$.
Received: September 22, 2020

Accepted: January 10, 2021

Correspondence

Osman H. Çam

Unalan Mh. Sarnıc Sokak, New City Istanbul No: 3/ A2/19, Uskudar, Istanbul, Turkey

Tel. +9050570184 70. Fax +90 2164674951

E-mail: osman.cam@gmail.com

Funding

None.

Conflict of interest

The Authors declare no conflict of interest.

How to cite this article: Çam OH, Milk DG, Alfaro-Iraheta F, et al. Endoscopic balloon dilatation of the olfactory cleft - a feasibility study of a novel technique in cadavers. Acta Otorhinolaryngol Ital 2021;41:168-172. https://doi. org/10.14639/0392-100X-N1132

(C) Società Italiana di Otorinolaringoiatria e Chirurgia Cervico-Facciale

\section{cc) (i) $\$$}

This is an open access article distributed in accordance with the CC-BY-NC-ND (Creative Commons Attribution-NonCommercial-NoDerivatives 4.0 International) license. The article can be used by giving appropriate credit and mentioning the license, but only for non-commercial purposes and only in the original version. For further information: https:// creativecommons.org/licenses/by-nc-nd/4.0/deed.en 
Similarly, surgical interventions are reserved for identifiable causes when medical treatment has not resulted in clinical improvement, e.g., endoscopic sinus surgery for chronic rhinosinusitis, septoplasty for nasal obstruction ${ }^{6}$. When surgery is undertaken on the olfactory cleft, it is usually in the context of skull base tumour resection, which ultimately results in resection of not only mucosa but also the olfactory apparatus. At present, surgical intervention is not considered for patients with idiopathic olfactory dysfunction or post-viral hyposmia.

This paper aims to describe the technical steps for endoscopic balloon dilatation of the olfactory cleft with the view of providing clinical applicability of this novel technique.

\section{Materials and methods}

\section{Ethical considerations}

This study was approved by the Central University Research Ethics Committee of the University of Liverpool (reference 4473). A total of ten nasal cavities were utilised for this study, fresh-frozen adult cadaver heads without a previous history of sinonasal surgery.

\section{Balloon dilatation of the olfactory cleft}

Two fellowship-trained rhinologists undertook all endoscopic, endonasal balloon dilatation and surgical dissections at the Human Anatomy Resource Centre at the University of Liverpool. Surgical dissection was performed with a $4 \mathrm{~mm} 30^{\circ}$ rigid endoscope connected to a high-definition monitor and camera system, utilising standard endoscopic sinus surgery instrumentation (Karl Storz, Tuttlingen, Germany).

Both $6 \mathrm{~mm}$ and $7 \mathrm{~mm}$ diameter balloons of the XprESS LoProfile ENT dilatation system (Stryker Entellus Medi-
$\mathrm{cal}^{\mathrm{TM}} \mathrm{MN}, \mathrm{USA}$ ) were utilised in this study (Fig. 1A). The device's malleable tip was configured for the sphenoid sinus using the supplied bending tool (Fig. 1B).

After the nasal cavity was irrigated with sterile water, endoscopic inspection of the olfactory cleft was performed, and debris was suctioned (Fig. 2A). The anatomical insertion of the middle turbinate to the skull base was then identified. An imaginary horizontal line was drawn across the leading edge of the turbinate bisecting the half of the vertical height between the skull base and the inferior edge of the middle turbinate (Fig. 2B). The dilatation device's tip was inserted under direct endoscopic vision into the area between the nasal septum and middle turbinate, bisecting the middle turbinate half-height (Fig. 3A). With the device held stable, the LED light fiber was advanced to facilitate endoscopic confirmation of the position of the instrument tip with the skull base. The balloon was then inflated for 20 seconds using the supplied inflation syringe (Fig. 3B).

\section{Post-dilatation inspection of the olfactory cleft}

After completing the olfactory cleft dilatation, the mucosa overlying the olfactory cleft and perpendicular plate of ethmoid was inspected for tears or defects. The mucosa was then elevated to expose the underlying bone (Fig. 4A). To accentuate any potential bony defects or fracture lines, we irrigated the exposed bony area with diluted blue food dye before the endoscopic inspection was repeated (Fig. 4B). The presence of any bony defect in the skull base and perpendicular plate of ethmoid was recorded. The process was then repeated for all nasal cavities, as described above.

\section{Results}

Endoscopic balloon dilatation of the olfactory cleft was completed in 10 nasal cavities. Six were dilated with the $6 \mathrm{~mm}$ bal-
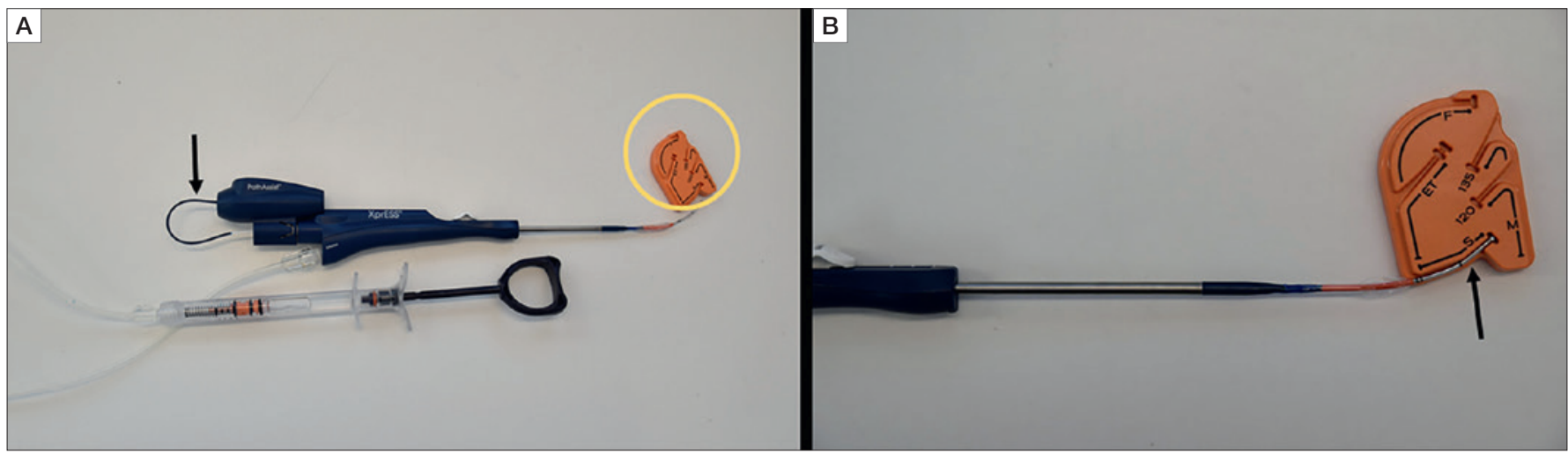

Figure 1. (A) XprESS LoProfile Ent Dilatation System. (B) Bender configured to sphenoid sinus (yellow circle; special bender, down arrow; led light fibre advancer, up arrow; tip of the dilatation system). 


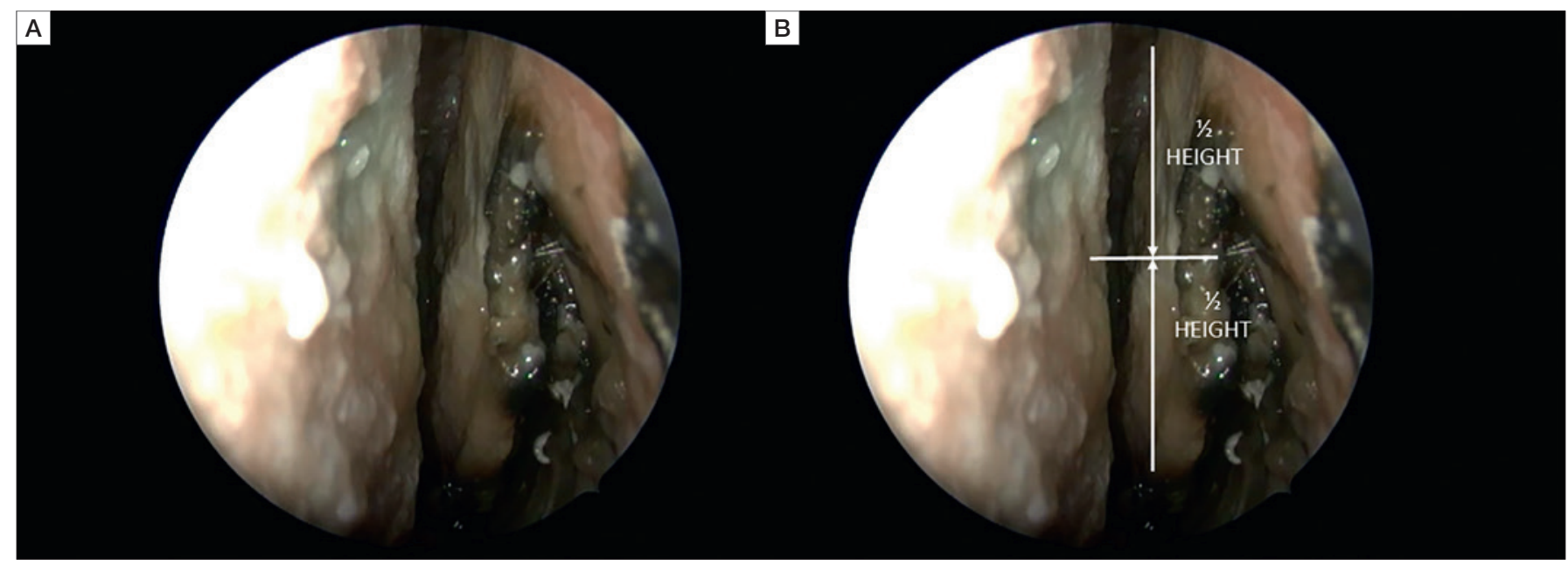

Figure 2. (A) Left nasal cavity, $0^{\circ}$ endoscopic view. (B) The imaginary line is drawn to bisect half-height of the middle turbinate.

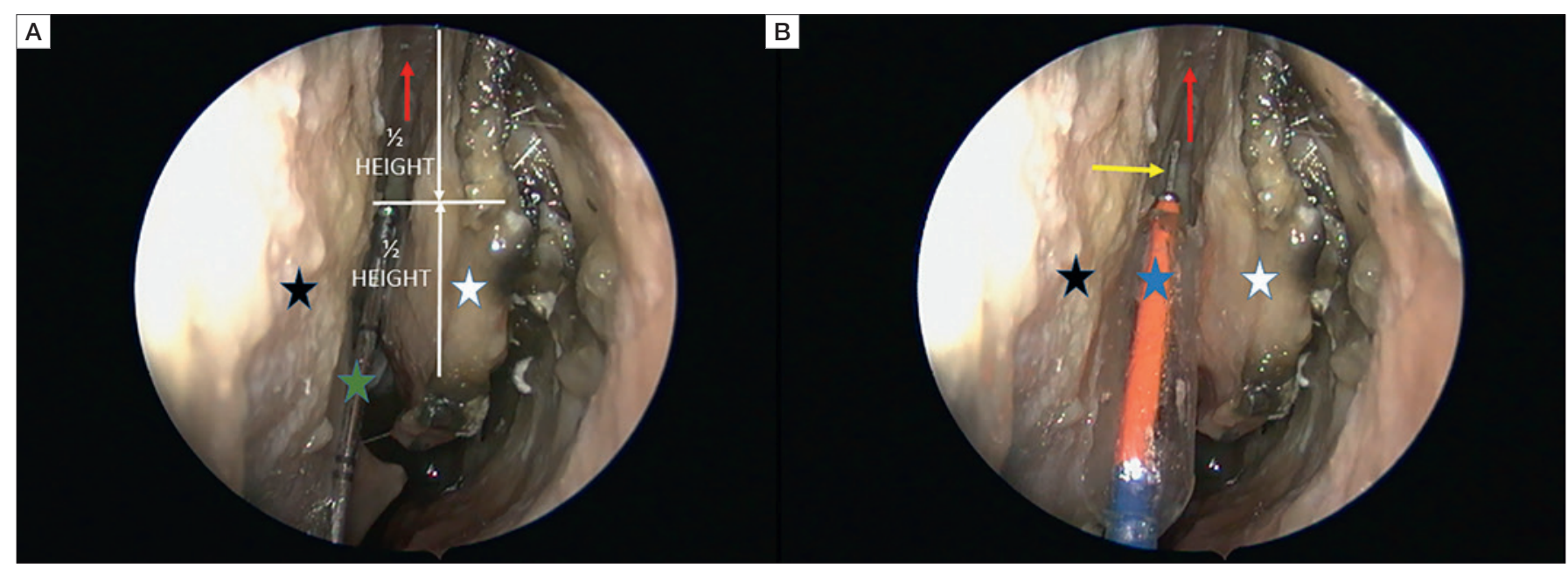

Figure 3. Left nasal cavity, $0^{\circ}$ endoscopic view. (A) Advancement of the tip of the probe to the imaginary line. (B) The inflation of the balloon for 20 sec in the olfactory groove (red arrow; skull base, black star; nasal septum, white star; middle turbinate, green star; the guide probe of the balloon device, yellow arrow; the led light fibre, blue star; the balloon of the device).

loon, and the remaining four with the $7 \mathrm{~mm}$ balloon. No tears or defects of the overlying mucosa were observed following balloon dilatation. After the mucosa was resected and the area irrigated with blue dye, no fractures or defects of the skull base were identified. However, one fracture oriented longitudinally was noted on the perpendicular plate of the ethmoid following dilatation with the $6 \mathrm{~mm}$ balloon (Fig. 5).

\section{Discussion}

Synopsis of key/new findings

This study has described a novel technique of balloon dilatation of the olfactory cleft utilising standard, commercially-available sinus dilatation devices. The technical steps have been described in detail, and in our experience, this minimally invasive procedure is both straightforward and repeatable with a short learning curve. Additional instruments, such as those typically required for sinus surgery, were not utilised to complete the procedure.

This study has also attempted to address the safety aspects of this novel technique. Neither the $6 \mathrm{~mm}$ and $7 \mathrm{~mm}$ diameter balloons caused trauma to the mucosa or the skull base's underlying bone. A single fracture was observed in one nasal cavity, which was localised to the ethmoid's perpendicular plate. This fracture line was horizontally oriented in the sagittal plane and was over $5 \mathrm{~mm}$ away from the bony skull base. Despite the relative risk of bony injury occurring with- 


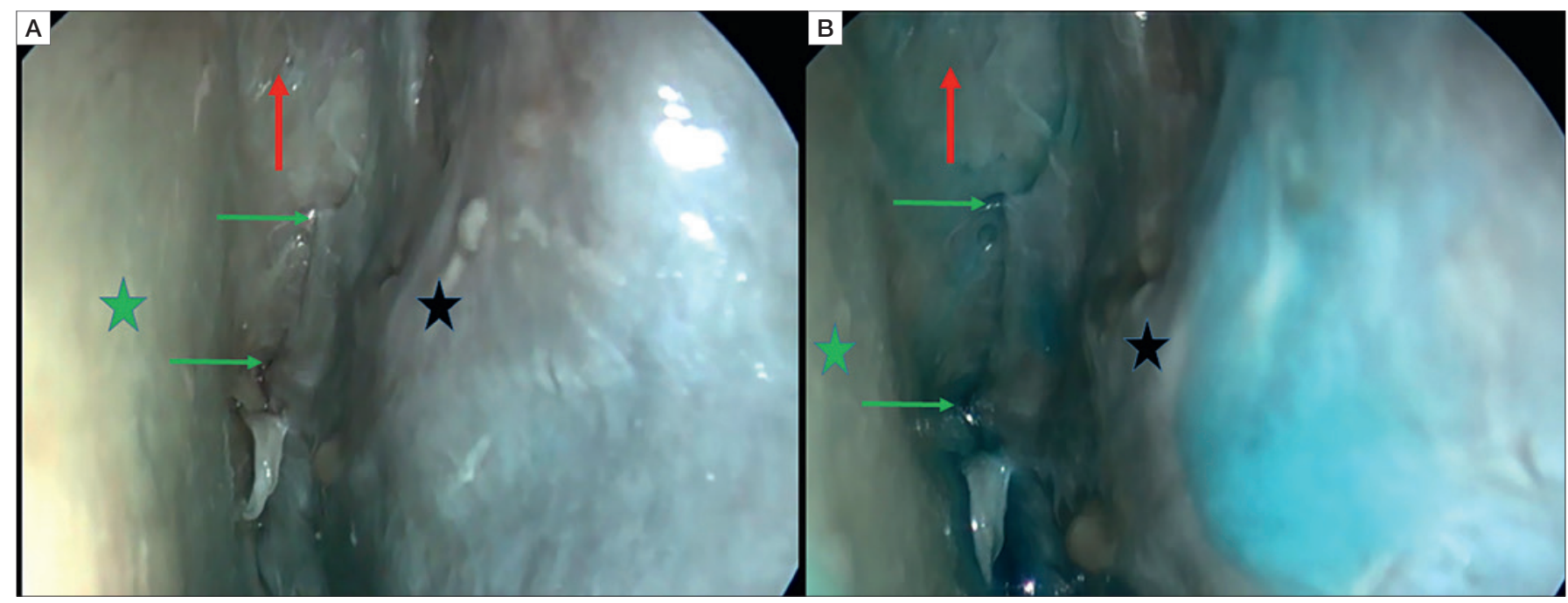

Figure $4.30^{\circ}$ endoscopic view of left olfactory groove, mucosal flap elevated. (A) Skull base and cribriform plate exposure with dissection. (B) The blue dye in introduced in order to see fracture lines (red arrow; skull base, green arrows; cribriform plate and olfactory nerve fibres, black star; elevated mucosal flap, green star; perpendicular plate of the ethmoid bone).

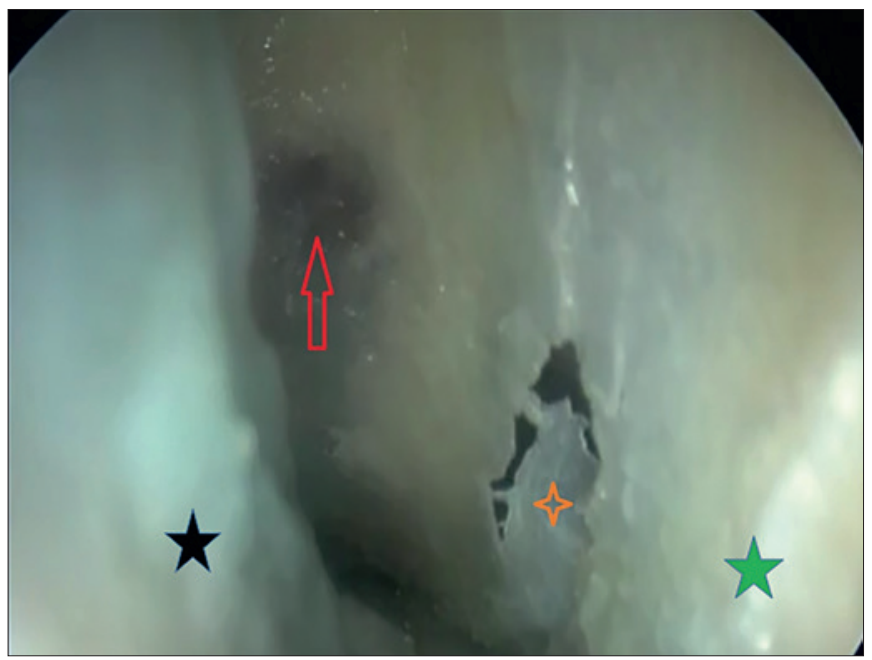

Figure $5.30^{\circ}$ Endoscopic view of the right olfactory groove (red arrow; skull base, green star; perpendicular plate, black star; elevated mucosa, orange diamond; fracture in the perpendicular plate).

in the olfactory cleft following balloon dilatation, we believe that the fracture occurred in a "controlled" manner.

\section{Strengths of the study}

The dilatation device utilised in this study exerted 12-gauge atmospheric pressure (atm) consistently around all surfaces of the balloon when it is dilated with the accompanying inflation syringe. Although the pressure exerted along the surface of the balloon appears high, it should be remembered that the expansion of the balloon is limited to the maximum diameter of either $6 \mathrm{~mm}$ or $7 \mathrm{~mm}$, and the over- all pressure is distributed evenly throughout the surface of the balloon. This contrasts with a study measuring the magnitude of the forces exerted during punch osteotomy with a Blakesley forceps, where the authors reported that it required $17.80 \mathrm{~N}$ to breach the bony cribriform plate ${ }^{7}$. A follow-on study by the same group highlighted that caution might be required in extrapolating force estimates from cadaver tissue to those required in living patients, which were typically higher ${ }^{8}$.

In this study, the midpoint vertical height of the middle turbinate was used as a reference point to introduce the curved tip of the device. The insertion was undertaken with full endoscopic visualisation of the skull base. The LED light fibre was advanced to confirm the tip's position in relation to the skull base before the balloon was introduced by fully advancing the balloon slide mechanism forward to position the balloon within the olfactory cleft. The requirement to fully visualise the anatomy and device may preclude the need for image guidance or fluoroscopic confirmation. Thus, a deviated nasal septum that obstructs visualisation of the area medial to the middle turbinate would be a relative contraindication to balloon dilatation of the olfactory cleft.

\section{Comparisons with other studies}

Olfactory cleft dilatation is a relatively new concept, first described in $2018^{3}$. The authors described their experience with three patients suffering from olfactory dysfunction. The surgical technique undertaken consisted of lateral fracture-dislocation of the lateral wall of the olfactory cleft (i.e., middle turbinate) using a Cottle elevator and a 
curved olive-shaped blunt aspirator. The authors reported improved access to the olfactory cleft, with minimal trauma to the mucosa. However, it should be recognised that this technique is not repeatable and is surgeon specific. The pressure exerted by the elevator is uncontrolled and dependent on tactile feedback.

In contrast, our technique allows for controlled and uniform pressure to be exerted along the balloon's entire length. Given that the balloon was not in contact with the bony skull base superiorly, inadvertent trauma can safely be avoided when the balloon is dilated. The additional step of advancing the LED light probe to check the position of the device tip in its proximity to the skull base before dilatation offers additional assurance that the integrity of the skull base is not violated ${ }^{9}$.

Additionally, the dilatation of the olfactory groove with the balloon device is a safe method in terms of vascular injuries (septal branches of the anterior ethmoid artery) when compared to surgical interventions while working in this region ${ }^{10}$.

\section{Clinical applicability of the study}

It is acknowledged that the efficacy of this intervention remains unproven in real clinical conditions and that the results described here should not be extrapolated as an indication that the technique is safe. It should be reiterated that further studies are required to ensure repeatability and veracity of the results. Nevertheless, the ability to dilate the olfactory cleft, as demonstrated in this study, opens the real possibility of offering patients who suffer from olfactory dysfunction (e.g., hyposmia) a minimally invasive intervention to maximise penetration of topical medication such as corticosteroids into this area, which is abundant with olfactory mucosa ${ }^{11}$. Patients with post-viral olfactory dysfunction who have not improved with conventional treatments (e.g., topical intranasal steroid) may be a specific patient group to potentially benefit from this intervention. Constitutional stenosis can be mentioned.

The degree of dilatation or topical medication penetrating this area was not evaluated in this report. Indeed, whether balloon dilatation caused significant lateralisation of the middle turbinate and the resultant effects of topical penetration into the osteomeatal complex is unknown. Nevertheless, these issues are the subject of further evaluation by this research team.

\section{Conclusions}

Endoscopic olfactory cleft dilatation appears to be a viable technique to improve access into this anatomical region. Our study suggests that the technique is both safe and associated with a short learning curve. Given that many patients suffering from olfactory dysfunction still do not derive satisfactory outcomes from contemporary treatment modalities, the clinical efficacy of olfactory cleft dilatation should be evaluated.

\section{References}

1 Whitcroft KL, Hummel T. Clinical diagnosis and current management strategies for olfactory dysfunction: a review. JAMA Otolaryngol Head Neck Surg 2019;145:846-853. https://doi.org/10.1001/ jamaoto.2019.1728

2 Temmel AF, Quint C, Schickinger-Fischer B, et al. Characteristics of olfactory disorders in relation to major causes of olfactory loss. Arch Otolaryngol Head Neck Surg 2002;128:635-641. https://doi. org/10.1001/archotol.128.6.635

3 Jankowski R, Nguyen DT, Gallet P, et al. Olfactory cleft dilatation. Eur Ann Otorhinolaryngol Head Neck Dis 2018;135:437-441. https:// doi.org/10.1016/j.anorl.2018.05.008

4 Damm M, Temmel A, Welge-Lussen A, et al. Riechstorungen Epidemiologie und Therapie in Deutschland, Osterreich und der Schweiz. HNO 2004;52:112-120. https://doi.org/10.1007/s00106-003-0877-z

5 Hummel T, Reden KRJ, Hähner A, et al. Effects of olfactory training in patients with olfactory loss. Laryngoscope 2009;119:496-499. https://doi.org/10.1002/lary.20101

6 Hummel T, Whitcroft KL, Andrews P, et al. Position paper on olfactory dysfunction. Rhinol Suppl 2017;54:1-26. https://doi.org/10.4193/ rhino16.248

7 Ross PD, Joice P, Nassif RG, et al. Surgical instrument force exerted during endoscopic sinus surgery: differences within the ethmoid sinus complex. Am J Rhinol Allergy 2010:24;76-80. https://doi. org/10.2500/ajra.2010.24.3374

8 Joice P, Ross PD, Wang D, et al. Measurement of osteotomy force during endoscopic sinus surgery. Allergy Rhinol (Providence) 2012;3:e61-65. https://doi.org/10.2500/ar.2012.3.0032

9 Lund VJ, Stammberger H, Fokkens WJ, et al. European position paper on the anatomical terminology of the internal nose and paranasal sinuses. Rhinol Suppl 2014;24:1-34.

10 Turri-Zanoni M, Arosio AD, Stamm AC, et al. Septal branches of the anterior ethmoidal artery: anatomical considerations and clinical implications in the management of refractory epistaxis. Eur Arch Otorhinolaryngol 2018;275:1449-1456. https://doi.org/10.1007/ s00405-018-4964-x

11 Jankowski R, Perrot C, Nguyen D, et al. Structure of the lateral mass of the ethmoid by curved stacking of endoturbinal elements. Eur Ann Otorhinolaryngol Head Neck Dis 2016;133;325-329. https://doi. org/10.1016/j.anorl.2016.07.007 